Department of Mechanics and Automation Engineering, Lviv Polytechnic National University, Ukraine, Lviv, S. Bandery Street 12, E-mail: vitalii.m.korendii@lpnu.ua

\title{
DYNAMICS OF TWO-MASS MOBILE VIBRATORY ROBOT WITH ELECTROMAGNETIC DRIVE AND VIBRO-IMPACT OPERATION MODE
}

Received: June 12, 2018 / Revised: September 19, 2018 / Accepted: December 26, 2018

(C) Korendiy V., 2018

\begin{abstract}
The purpose of research. Substantiation of inertial, stiffness and excitation parameters of mechanical oscillatory system of mobile vibratory robot in order to maximize its motion speed. Methodology. The technique of the research is based on fundamental concepts of engineering mechanics and theory of mechanical vibrations. In order to deduce the differential equations of motion of the mechanical system of mobile vibratory robot the Lagrange second order equations were used. The computation modelling of the system's motion caused by periodic excitation forces was carried out using MathCAD software. Results. The design diagram (model) of the two-mass mobile vibratory system with electromagnetic drive was constructed. The mathematical model of its motion was developed and the parameters of the resonance vibro-impact mode of its operation were substantiated. The steady-state and transient conditions of operation of the system under the influence of periodic excitation force of various magnitude were investigated. Scientific novelty. The structure of mobile vibratory device designed on the basis of two-mass oscillatory system with vibro-impact operation mode was substantiated. The differential equations of motion of the proposed system were set up taking into account the nonlinear stiffness characteristic of the elastic element connecting two oscillating bodies. The influence of the system's excitation parameters on its motion speed was analysed. This allows to substantiate the rational magnitude and frequency of the excitation force. Practical value. The results of the carried-out investigations can be used while designing and developing control systems of mobile vibratory transporting and robotic devices in order to ensure the possibility of changing the speed of their motion without changing the inertial and stiffness parameters of their mechanical oscillating systems. Scopes of further investigations. While carrying out further investigations it is necessary to study the possibility of changing the nonlinearity of stiffness characteristic of the elastic element in order to change the kinematic parameters of the system's motion. In addition, it is necessary to substantiate the mechanisms of changing the direction of motion of mobile vibratory robot.
\end{abstract}

Keywords: mobile vibratory robot, vibration exciter, vibro-impact operation mode, inertial parameters, stiffness parameters, excitation parameters, electromagnetic drive.

\section{Introduction}

Nowadays, in almost each industrially developed country, there are actively performed the investigations related with creation of mobile robots. This is explained by the necessity to transport different cargos and to carry out technological operations in inaccessible or hard-to-reach places for human beings, as well as on the territories with "aggressive" environments where the human presence is under danger. One of the most prospective methods of mobile robots' motion, which is being actively developed in recent years, consists in the use of controlled vibratory motion of internal masses placed inside the body of the robot. By changing the parameters of the masses' motion (direction, speed, and acceleration), one can control the reaction force of the environment acting upon the robot's body, which ensures its motion in the necessary direction and with the necessary speed. 


\section{Dynamics of Two-mass Mobile Vibratory Robot with Electromagnetic Drive and Vibro-impact ...}

One of the simplest diagrams of vibratory robot designed on the basis of single-mass oscillatory system is presented in Fig. 1, a. The working body of the device is placed on the supporting surface with a help of thin rods attached to the body by elastic elements of stiffness $c$. These elastic elements are inclined to the supporting surface at the angle $\varphi$. Due to the influence of the alternating force $F(t)$, whose line of action is inclined to the rods' axes at the angle $\varphi_{1}$, the directional oscillations of the working mass $m$ occur causing the "jumping" motion of the robot along the supporting surface in certain direction.

In Fig. 1, b, there is presented the two-mass structure of the vibratory robot whose working bodies are attached by the elastic element $c$. The alternating excitation force $F(t)$ is applied between the masses $m_{1}$ and $m_{2}$. The motion of the robot is performed due to the asymmetrical friction between the working masses and the supporting surface. The magnitude of the friction force depends on the motion direction (in one direction the coefficient of friction is significantly larger than in the other direction).

The next diagram of the mobile vibratory device is presented in Fig. 1, c. In this case, the two-mass oscillatory system of the robot consists of two bodies $m_{1}$ and $m_{2}$ attached by the elastic element of stiffness $c$. The excitation force is formed by the centrifugal inertial forces caused by rotation of unbalanced masses $m_{3}$ and $m_{4}$. The translational motion of the robot can be provided by means of rational choosing of inertial and stiffness parameters of the system and the frequencies of the unbalanced masses rotation.

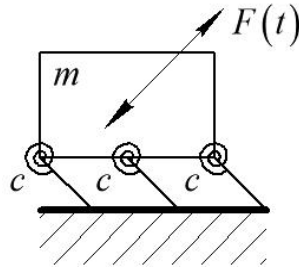

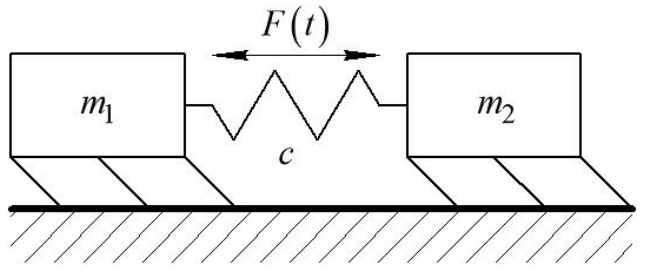

b

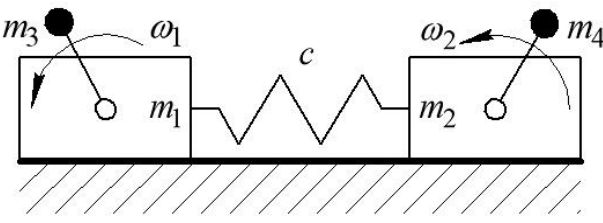

Fig. 1. Simplest diagrams of mobile vibratory devices

\section{Review of modern information sources on the subject of the paper}

The general overview of mobile vibratory robots with some aspects of investigation of the certain structures is presented in $[1,2]$. Also, there are discussed the requirements needed to provide the robots' motion along a rough surface, in particular, the phenomenon of friction asymmetry [1] or one-way bearings [2]. In [3], the authors investigated the mobile vibratory system based on the Duffing oscillator with a cubic spring. The device was excited by alternating force acting between the internal mass and the working body. Unlike in the other mobile vibro-impact devices, the use of a cubic spring with nonlinear stiffness allowed to simplify the structure of the device and the control algorithm, as well as to provide the nonimpact operation mode.

The detailed investigations of various types of vibratory robots are presented in the works [4-8]. Each design of vibratory robot was described by the corresponding mathematical model taking into account different characteristics of elastic elements (linear, piecewise linear, nonlinear) and of the electromagnet drive (single-cycle, double-cycle). The translational motion of most systems was provided using friction asymmetry at the working body-surface contact. Some designs of vibratory robots used the effect of vibro-impact provided by electromagnetic drive and piecewise linear characteristic of the elastic element, which ensure stepwise straight-line motion of the robots.

In publications $[9,10]$, the authors studied a capsule-type vibratory robot moving in pipeline environment with non-smooth friction. The robots moved due to the operation of a vibro-impact oscillator placed inside the capsule. The authors investigated various control parameters, e.g. impact stiffness, frequency and amplitude of excitation with the purpose to ensure the fastest progression of the system.

In this paper, the author will continue his previously performed investigations [11, 12] studying the mobile vibratory robot with electromagnetic drive and vibro-impact operation mode. 


\section{Vitaliy Korendiy}

\section{Objectives and problems of research}

The main purpose of the research consists in substantiation of inertial, stiffness and excitation parameters of mechanical oscillatory system of mobile vibratory robot in order to maximize its motion speed. With the aim to achieve this goal, the following tasks will be considered: 1) general overview of the process of vibratory motion of mobile robots; 2) constructing the design diagram of the mobile vibratory robot with vibro-impact operation mode; 3 ) developing the mathematical model of the robot's dynamics; 4) modelling the robot's motion on the basis of the derived differential equations in MathCAD software; 5) analysis of influence of the excitation parameters on the system's motion speed; 6) simulation of the robot's motion in SolidWorks software; 7) comparison of results obtained theoretically and experimentally.

\section{The idea of operation of vibratory robot}

In this paper, the possibility of developing the mobile robotic device designed on the basis of twomass oscillatory system with vibro-impact operation mode will be substantiated. One of the possible designs of such systems is presented in Fig. 2. It consists of the platform (frame, body) 1, on which there is placed the exciting mass 2 attached to the body 1 with a help of the elastic element 2 . The exciting mass 2 can freely slide over the surface of the platform 1 that is placed on the unmovable supporting surface (plate) 4. In order to perform vibro-impact effect, there is used the additional "impact" (restricting) spring 5 with the plate 6 attached to its end. The other end of the restricting spring 5 is attached to the platform 1 . All the bodies of the system, in particular, the exciting mass 3 and the platform 1, can step-wisely move in single direction parallel to the supporting surface 4 .

The motion of the vibratory robot is performed as follows. The alternating excitation force directed horizontally is applied to the body 3 . The vibration exciter can be of the electromagnetic type. When the exciting mass reaches the amplitude equal to the clearance between the body 3 and the restricting plate 6 , there occurs the vibro-impact effect due to the sudden change of stiffness of the oscillatory system. The change of stiffness can be explained by including the additional restricting spring 5 into the oscillatory system of vibratory device. The stiffness of this spring is much larger than the stiffness of the main elastic element 2. As a result of sudden changing of the system's stiffness, the inertial forces caused by the accelerated motion of the exciting mass 3 are transmitted through the restricting spring 5 to the platform 1 and provide its motion with respect to the unmovable supporting plate 4 . Thus, after each contact of the body 3 with the restricting plate 6 , there occurs stepwise displacement of the platform 1 in horizontal direction that corresponds to the direction of the spring's 5 compression. In order to ensure the maximal speed of the platform's 1 motion, it is necessary that the inertial force of the exciting body 3 at the impact moment is as larger than the friction force between the supporting surface (plate 4) and the platform 1 as possible. Therefore, we will consider the motion speed as one of the main criterions of the vibratory robot efficiency and investigate the influence of the excitation parameters on this speed.

\section{Constructing the calculation diagram of the robot}

In this chapter of the paper, we will present the calculation diagram of the mechanical oscillatory system of mobile vibratory robot and analyse the basic forces acting upon the bodies of the system. The obtained results will be used in further chapters while developing the mathematical model of the robot's dynamics and deriving the differential equation of the robot's motion.

On the basis of the simplified designed diagram of the mobile vibratory device (Fig. 2) proposed in the previous chapter, let us construct its three-dimensional calculation diagram (Fig. 3). Let us adopt the following notations: $m$ is the mass of the exciting body $3 ; M$ is the mass of the platform 1 (without the mass of the exciting body); $c, \mu, c_{1}, \mu_{1}$ are the coefficients of stiffness and damping of elastic elements 2 and 5 , respectively; $\Delta$ is the initial clearance between the exciting body 3 and the platform 1 (or the length of the elastic element 2 in its free state); $x_{1}$ is the horizontal coordinate of the mass centre of the exciting body with respect to the unmovable reference system $x O y ; x_{2}$ is the coordinate of an arbitrary point on the platform 1 with respect to the unmovable reference system $x O y ; F_{3 \sigma}$ is the excitation force 


\section{Dynamics of Two-mass Mobile Vibratory Robot with Electromagnetic Drive and Vibro-impact ...}

applied horizontally between the bodies 1 and $3 ; N_{1}, N_{2}$ are the normal reactions of the supporting surface 4 acting on the platform 1 and of the platform 1 acting on the exciting body 3 , respectively; $F_{T 2}$ is the friction force occurring as a result of sliding of the exciting body 3 over the platform $1 ; F_{T 1}$ is the friction force occurring as a result of sliding of the platform 1 over the supporting surface 4 .

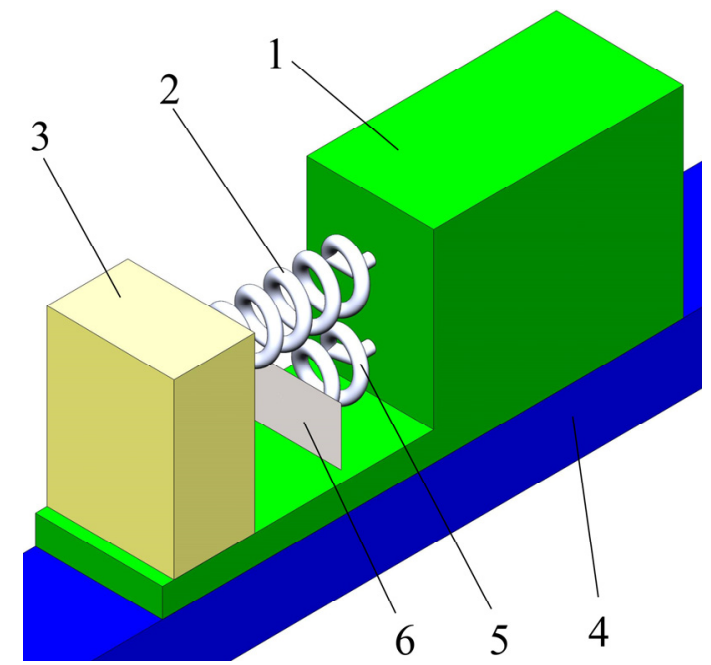

Fig. 2. Simplified design diagram of the twomass vibratory device with vibro-impact operation mode

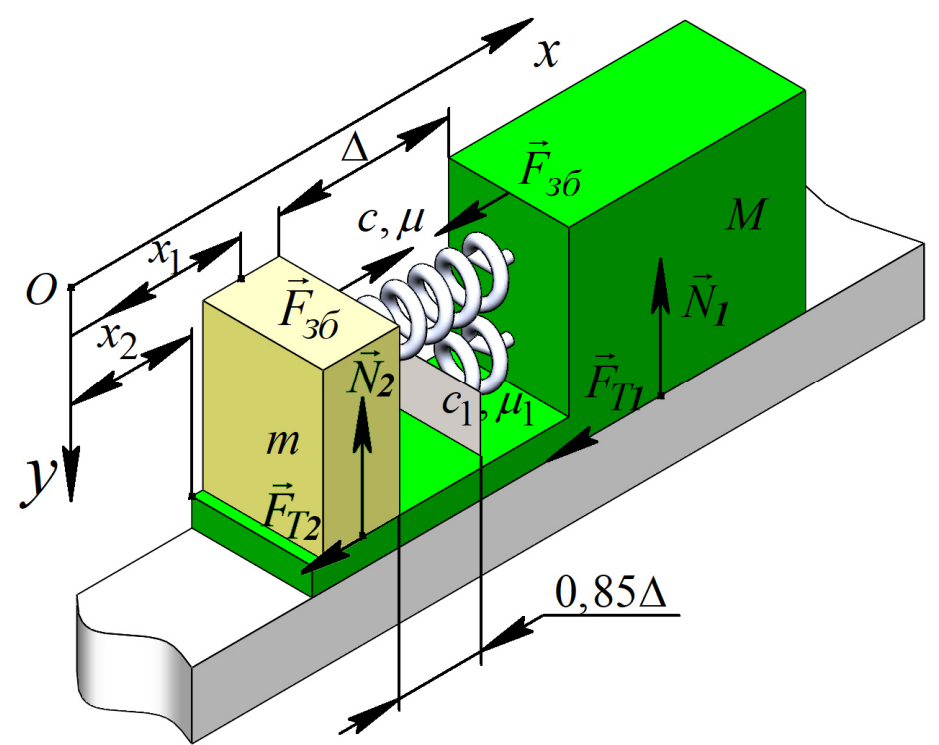

Fig. 3. Simplified calculation diagram of the mechanical oscillatory system of mobile vibratory device

The working bodies (the exciting mass $m$ and the platform $M$ ) have the possibility to move along the horizontal axis $O x$ and are considered as perfectly rigid bodies. For describing the motion of each mass, we used the corresponding generalized coordinated $x_{1}$ and $x_{2}$. While developing the mathematical model of the mechanical oscillatory system of vibratory robot and while carrying out further investigations, let us neglect the geometrical sizes and shapes of the working bodies considering them as material points (mass points or particles). Let us also assume that the bodies are connected by elastic-viscous elements with stiffnesses $c, c_{1}$ and damping coefficients (coefficients of viscous friction) $\mu, \mu_{1}$. While describing the potential forces, let us assume that deformations of the elastic elements are performed in accordance with the linear Hooke's law.

The working bodies of the mechanical oscillatory system are acted by alternating excitation forces $F_{36}$ provided by the electromagnetic drive. The bodies are also influenced by alternating forces of tension/compression and viscous friction of the corresponding elastic elements 2 and 5 with stiffnesses $c$, $c_{1}$ and damping coefficients (coefficients of viscous friction) $\mu, \mu_{1}$. As a result of interaction of the exciting mass 3 with the platform 1 and of the platform 1 with the supporting surface 4 , the working bodies are acted by the friction forces $F_{T 1}$ and $F_{T 2}$, whose directions depend on the motion direction of corresponding masses.

As it was mentioned above, the excitation forces are represented by the alternating forces $F_{3 \sigma}$ provided by the electromagnetic drive. By choosing the rational inertial, stiffness and excitation parameters of the mechanical oscillatory system of mobile vibratory device (e.g. the forced frequency and the amplitude of the excitation force), it is possible to ensure the optimal translational motion (maximal-speed motion) of the vibratory robot in positive direction of the $O x$ axis (i.e. in the direction of compression of the restricting spring 5). This task requires deriving the differential equations of the system's motion with further substantiation of its optimal parameters and operation modes in order to ensure the maximal motion speed of the mobile vibratory device. 


\section{Vitaliy Korendiy}

\section{Developing the mathematical model of the robot's motion}

In order to derive the differential equations of the mechanical oscillatory system's motion, let us use the Lagrange's second order equations. Let us consider the non-steady translational motion of the mobile vibratory robot along the horizontal rough surface. Let us adopt the displacement of the exciting mass's centre $x_{1}$ and the displacement of the platform $x_{2}$ as the generalized coordinates. The Lagrange's second order equations for the considered mechanical oscillatory system are of the following form:

$$
\frac{d}{d t} \frac{\partial T}{\partial \dot{x}_{i}}-\frac{\partial T}{\partial x_{i}}=Q_{i}, \quad i=1,2,
$$

where $T$ is the kinetic energy of the mechanical oscillatory system of mobile vibratory device; $Q_{i}$ are the generalized forces acting on the bodies of the system and corresponds to the chosen generalized coordinates $x_{i} ; \dot{x}_{i}$ are the generalized velocities of the corresponding bodies of the system which corresponds to the chosen generalized coordinates $x_{i}$.

Taking into account the fact that the exciting body performs the translational motion with respect to the platform of the vibratory device with the absolute speed $\dot{x}_{1}$, and the platform moves translationally with respect to the unmovable supporting surface with the speed $\dot{x}_{2}$, the kinetic energy of the mechanical oscillatory system can be determined by the following formula:

$$
T=\frac{m \cdot \dot{x}_{1}^{2}}{2}+\frac{M \cdot \dot{x}_{2}^{2}}{2}
$$

The platform of the vibratory device is acted by one external force in the direction of its motion. This force is the friction force $F_{T 1}$ between the platform and the supporting surface. One more friction force $F_{T 2}$ acts between the platform and the exciting body, however, for the considered system this force is internal one. The mentioned forces are always opposite to the related directions of the corresponding bodies' motion. Thus, we can write the following expressions:

$$
\begin{gathered}
F_{T 1}=-f_{1} \cdot N_{1} \cdot \operatorname{sign}\left(\dot{x}_{2}\right)=-f_{1} \cdot(M+m) \cdot g \cdot \operatorname{sign}\left(\dot{x}_{2}\right) ; \\
F_{T 2}=-f_{2} \cdot N_{2} \cdot \operatorname{sign}\left(\dot{x}_{1}-\dot{x}_{2}\right)=-f_{2} \cdot m \cdot g \cdot \operatorname{sign}\left(\dot{x}_{1}-\dot{x}_{2}\right),
\end{gathered}
$$

where $f_{1}, f_{2}$ are the coefficients of friction between the platform and the supporting surface and between the exciting body and the platform, respectively; $g$ is free-fall acceleration; $\operatorname{sign}\left(\dot{x}_{i}\right)$ is the function taking into account the direction of motion of the corresponding body (if the body's speed is positive, the function takes the value " 1 "; if the speed is negative, the function takes the value "- 1 "; if the speed equals " 0 ", the function takes the value " 0 ").

The internal forces acting in the considered mechanical oscillatory system of vibratory device consist of the elasticity force $F_{n p}$ and the dissipative force (the force of viscous friction) $F_{o n}$ of the elastic elements. In the considered system the elasticity force is piecewise linear. At the beginning of motion of the exciting body along the platform, the stiffness of the of the elastic element equals $c$, and at the moment when the body contacts the restricting plate (e.g., when the difference $x_{1}-x_{2}>0,85 \cdot \Delta$ ), the total stiffness of the elastic element increases to the value $c+c_{1}$. In some cases, the empiric coefficient 0,85 can be substantiated by the conditions of the absence of the contact between the armature and the winding when the electromagnetic drive is used. That is why, for modelling the forces of elasticity and viscous friction acting on the exciting body, we can use the following expressions:

$$
\begin{gathered}
F_{n p}=\left\{\begin{array}{l}
c \cdot\left(x_{1}-x_{2}\right), \text { if } x_{1}-x_{2}<0,85 \cdot \Delta ; \\
c \cdot\left(x_{1}-x_{2}\right)+c_{1} \cdot\left(x_{1}-x_{2}-0,85 \cdot \Delta\right), \text { if } x_{1}-x_{2} \geq 0,85 \cdot \Delta ;
\end{array}\right. \\
F_{\text {on }}=\left\{\begin{array}{l}
\mu \cdot\left(\dot{x}_{1}-\dot{x}_{2}\right), \text { if } x_{1}-x_{2}<0,85 \cdot \Delta ; \\
\left(\mu+\mu_{1}\right) \cdot\left(\dot{x}_{1}-\dot{x}_{2}\right), \text { if } x_{1}-x_{2}>0,85 \cdot \Delta .
\end{array}\right.
\end{gathered}
$$




\section{Dynamics of Two-mass Mobile Vibratory Robot with Electromagnetic Drive and Vibro-impact ...}

The excitation force $F_{36}$ is modelled in the form of periodic function changing in accordance with the sinusoidal law:

$$
F_{3 б}=F \cdot \sin (\omega \cdot t+\xi),
$$

where $F, \omega, \xi$ are the amplitude, circular frequency and initial phase of the excitation force, respectively; $t$ is time. The formula (6) with sufficient accuracy describes the excitation force when using the two-cycle electromagnetic drive.

Taking into account the formulas (3-6), the generalized forces located in the right sides of the differential equations (1) of the vibratory device's motion can be presented in the following form:

$$
\begin{gathered}
Q_{x_{1}}=F_{36}-F_{T 2}-F_{\text {on }}-F_{n p}= \\
=F \cdot \sin (\omega \cdot t+\xi)-f_{2} \cdot m \cdot g \cdot \operatorname{sign}\left(\dot{x}_{1}-\dot{x}_{2}\right)-\left\{\begin{array}{l}
c \cdot\left(x_{1}-x_{2}\right)+\mu \cdot\left(\dot{x}_{1}-\dot{x}_{2}\right), \text { if } x_{1}-x_{2}<0,85 \cdot \Delta ; \\
c \cdot\left(x_{1}-x_{2}\right)+c_{1} \cdot\left(x_{1}-x_{2}-0,85 \cdot \Delta\right)+ \\
+\left(\mu+\mu_{1}\right) \cdot\left(\dot{x}_{1}-\dot{x}_{2}\right), \text { if } x_{1}-x_{2}>0,85 \cdot \Delta ;
\end{array}\right. \\
Q_{x_{2}}=-F_{3 \sigma}+F_{T 2}-F_{T 1}+F_{o n}+F_{n p}=-F \cdot \sin (\omega \cdot t+\xi)+f_{2} \cdot m \cdot g \cdot \operatorname{sign}\left(\dot{x}_{1}-\dot{x}_{2}\right)- \\
-f_{1} \cdot(M+m) \cdot g \cdot \operatorname{sign}\left(\dot{x}_{2}\right)+\left\{\begin{array}{l}
c \cdot\left(x_{1}-x_{2}\right)+\mu \cdot\left(\dot{x}_{1}-\dot{x}_{2}\right), \text { if } x_{1}-x_{2}<0,85 \cdot \Delta ; \\
c \cdot\left(x_{1}-x_{2}\right)+c \cdot\left(x_{1}-x_{2}-0,85 \cdot \Delta\right)+ \\
+\left(\mu+\mu_{1}\right) \cdot\left(\dot{x}_{1}-\dot{x}_{2}\right), \text { if } x_{1}-x_{2}>0,85 \cdot \Delta .
\end{array}\right.
\end{gathered}
$$

After determining the corresponding partial derivatives of the expressions (2) of the system's kinetic energy and taking into account the derived expressions (7) for calculating the generalized forces, we can write the differential equations of the vibratory system's motion in the following form:

$$
\begin{gathered}
m \cdot \ddot{x}_{1}=F \cdot \sin (\omega \cdot t+\xi)-f_{2} \cdot m \cdot g \cdot \operatorname{sign}\left(\dot{x}_{1}-\dot{x}_{2}\right)-\left\{\begin{array}{l}
c \cdot\left(x_{1}-x_{2}\right)+\mu \cdot\left(\dot{x}_{1}-\dot{x}_{2}\right), \text { if } x_{1}-x_{2}<0,85 \cdot \Delta ; \\
c \cdot\left(x_{1}-x_{2}\right)+c_{1} \cdot\left(x_{1}-x_{2}-0,85 \cdot \Delta\right)+ \\
+\left(\mu+\mu_{1}\right) \cdot\left(\dot{x}_{1}-\dot{x}_{2}\right), \text { if } x_{1}-x_{2}>0,85 \cdot \Delta ;
\end{array}\right. \\
M \cdot \ddot{x}_{2}=-F \cdot \sin (\omega \cdot t+\xi)+f_{2} \cdot m \cdot g \cdot \operatorname{sign}\left(\dot{x}_{1}-\dot{x}_{2}\right)-f_{1} \cdot(M+m) \cdot g \cdot \operatorname{sign}\left(\dot{x}_{2}\right)+ \\
+\left\{\begin{array}{l}
c \cdot\left(x_{1}-x_{2}\right)+\mu \cdot\left(\dot{x}_{1}-\dot{x}_{2}\right), \text { if } x_{1}-x_{2}<0,85 \cdot \Delta ; \\
c \cdot\left(x_{1}-x_{2}\right)+c_{1} \cdot\left(x_{1}-x_{2}-0,85 \cdot \Delta\right)+ \\
+\left(\mu+\mu_{1}\right) \cdot\left(\dot{x}_{1}-\dot{x}_{2}\right), \text { if } x_{1}-x_{2}>0,85 \cdot \Delta .
\end{array}\right.
\end{gathered}
$$

It is very difficult to analytically solve the obtained system of differential equations (8). That is why, in further stages of our research, let us use the numerical methods implemented in applied computer software, in particular, in MathCAD. After this, the simulation of system's motion will be carried out using SolidWorks software and the obtained results will be compared.

\section{Numerical solving of the derived differential equations of the robot's motion}

The input data for performing the modelling the vibratory device's motion is following:

- inertial parameters of the investigated mechanical oscillatory system: $m=0.25 \mathrm{~kg}, M=5.5 \mathrm{~kg}$;

- stiffness and damping parameters of the main and restricting elastic elements: $c=100 \mathrm{~N} / \mathrm{m}$, $c_{1}=3000 \mathrm{~N} / \mathrm{m}, \mu \approx \mu_{1} \approx 0, \Delta=0,04 \mathrm{~m}$;

- excitation parameters: $F=100 \mathrm{~N}, \omega=30 \mathrm{rad} / \mathrm{s}(\approx 5 \mathrm{~Hz}), \xi=0$;

- initial parameters of modelling: initial length of the main elastic element is equal to its length in free state; initial position of the exciting mass $x_{1}(0)=0$, and of the platform $x_{2}(0)=0$; initial speeds of the oscillating masses $\dot{x}_{1}(0)=0, \dot{x}_{2}(0)=0$;

- friction parameters between the contacting surfaces: for the steel material of the contacting bodies, 


\section{Vitaliy Korendiy}

the coefficient of friction approximately equals $f_{1}=f_{2}=0,17$.

In order to simplify and to intensify the modelling process, let us investigate the system's motion neglecting the dissipation of energy in elastic elements and viscous friction between the contacting surfaces. The results of the motion modelling of mobile vibratory device at the time periods of $1 \mathrm{~s}$ and $5 \mathrm{~s}$ are presented in Figs. 4, a and b, respectively. The maximal amplitude of the exciting mass displacement from its equilibrium position is about $X_{1}=0,05 \mathrm{~m}$ and slightly exceeds the $85 \%$ of the free length of the main spring $\Delta=0,04 \mathrm{~m}$. This fact proves the operation of the restricting spring, as well as the vibroimpact effect providing the periodically discrete (stepwise) motion of the platform (Fig. 4, a, b).

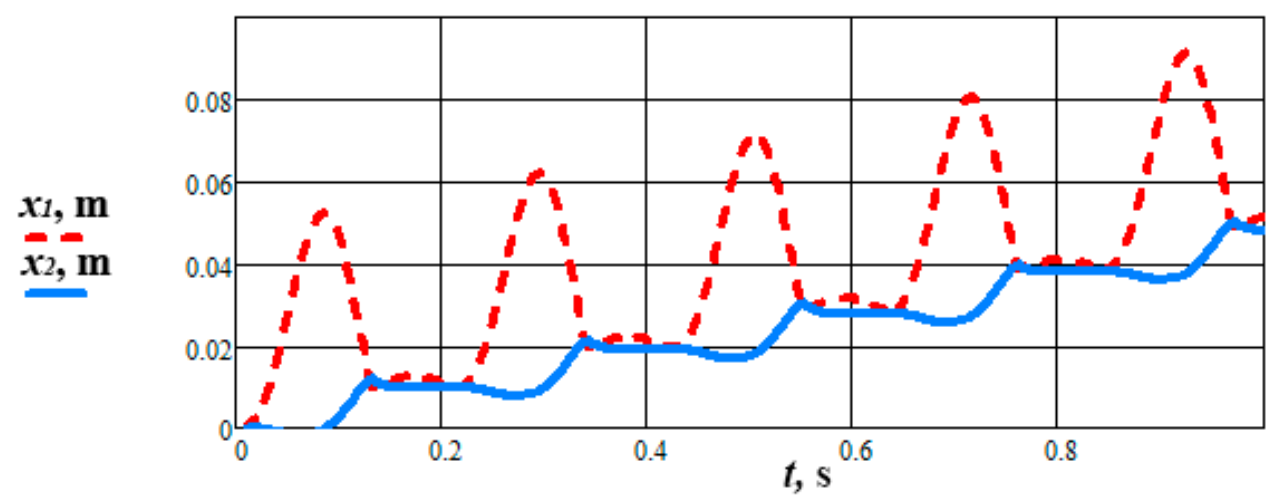

a

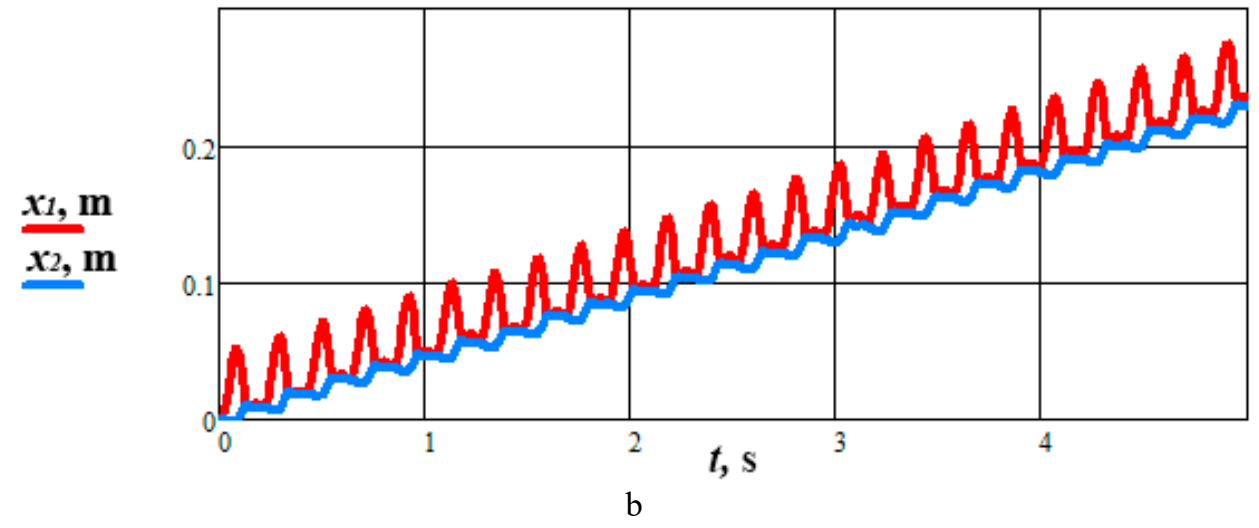

Fig. 4. Time dependencies of the oscillating masses displacements obtained in MathCAD software

The platform of the mobile vibratory device moves step-wisely with the average speed $0.05 \mathrm{~m} / \mathrm{s}$ (blue solid line in Fig. 4). The time dependence of the platform's instant speed is presented in Fig. 5 ( $\mathrm{a}-$ for the time period $1 \mathrm{~s} ; \mathrm{b}$ - for the first $5 \mathrm{~s}$ ).

Analysing Figs. 4 and 5, we can conclude that the motion of the mobile vibratory device is performed in accordance with the following principle. At the initial time moment, the speeds of the platform and of the exciting body are equal to zero. After applying the excitation force between the oscillating bodies of the system, the exciting mass begins to move almost according to sinusoidal law until the moment of contact with the restricting (impact) plate. In the case of contact, when the magnitude of the inertial force of the disturbing body is larger than the magnitude of the friction force between the platform and the supporting surface $\left(F_{T 1}=f_{1} \cdot(M+m) \cdot g\right)$, the body of the vibratory device receive some acceleration proportional to the inertial force of the disturbing mass $m$. As a result of vibro-impact effect, the speed of the disturbing body becomes smaller, whence the speed of the platform increases. While the specified inertial force is greater than the friction force, the body of the vibratory device moves in the direction of the inertial force. After a certain period of time, as a result of the action of friction forces, the body of the device gradually stops, and the disturbing mass begins a new cycle of its oscillatory motion with respect to the platform until it contacts with the restricting plate. Thus, the platform will be almost 
Dynamics of Two-mass Mobile Vibratory Robot with Electromagnetic Drive and Vibro-impact ... unmovable until the next impact of the disturbing body on the restricting plate occurs with the simultaneous fulfilment of the condition $m \cdot \ddot{x}_{1}>F_{T 1}$.

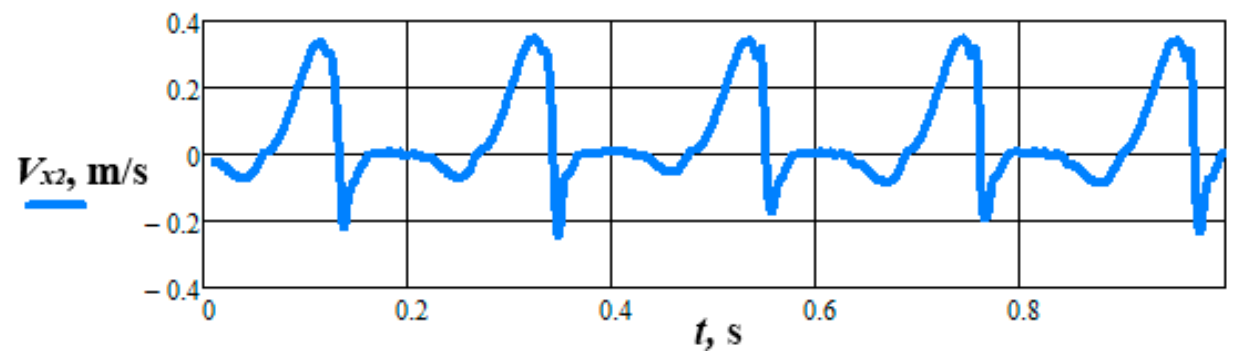

a

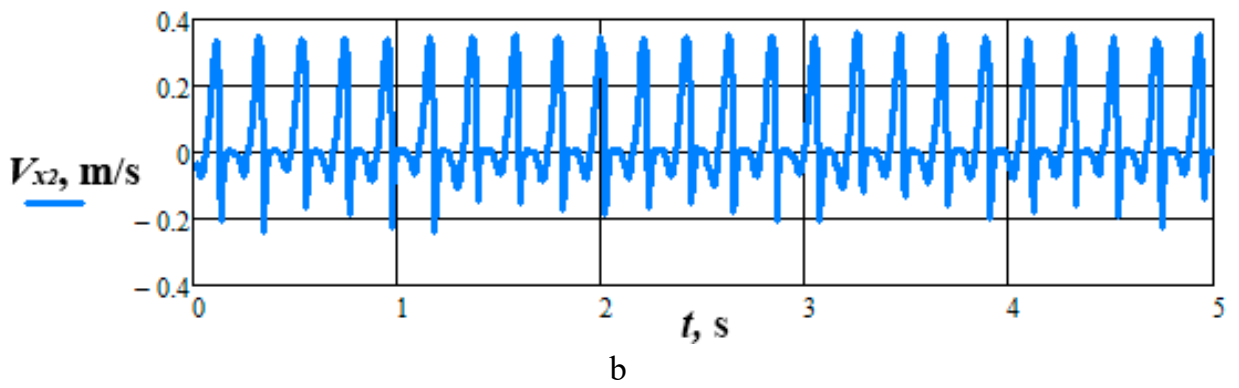

Fig. 5. Time dependencies of the platform speed changing

Analysing the influence of excitation parameters on the speed of robot's motion

The next stage of the present investigation consists in substantiation of excitation parameters of the mobile vibratory device with the purpose to ensure its maximal speed. In particular, it will be analysed the influence of changing the amplitude value (magnitude) and circular frequency of the excitation force on the motion speed of the robot.

For the unchanged inertial and stiffness parameters of the robot's mechanical oscillatory system presented above, let us investigate its speed at the following excitation parameters (see Table 1).

Table 1

Excitation parameters of the system with constant amplitude value of the disturbing force

\begin{tabular}{|l|l|}
\hline a) $F=100 \mathrm{~N}, \omega=10 \mathrm{rad} / \mathrm{s}(\approx 1.6 \mathrm{~Hz})$ & b) $F=100 \mathrm{~N}, \omega=20 \mathrm{rad} / \mathrm{s}(\approx 3.2 \mathrm{~Hz})$ \\
\hline c) $F=100 \mathrm{~N}, \omega=30 \mathrm{rad} / \mathrm{s}(\approx 4.8 \mathrm{~Hz})$ & d) $F=100 \mathrm{~N}, \omega=40 \mathrm{rad} / \mathrm{s}(\approx 6.4 \mathrm{~Hz})$ \\
\hline e) $F=100 \mathrm{~N}, \omega=50 \mathrm{rad} / \mathrm{s}(\approx 8 \mathrm{~Hz})$ & f) $F=100 \mathrm{~N}, \omega=60 \mathrm{rad} / \mathrm{s}(\approx 9.6 \mathrm{~Hz})$ \\
\hline
\end{tabular}

The results of modelling the system's motion for the amplitude value of the excitation force $F=100 \mathrm{~N}$ and different forced frequencies $10 \mathrm{rad} / \mathrm{s} \quad(\approx 1,6 \mathrm{~Hz}) \leq \omega \leq 60 \mathrm{rad} / \mathrm{s} \quad(\approx 9,6 \mathrm{~Hz})$ are presented in Fig. 6. Analysing the obtained results, we can conclude that in the cases a) and b) (i.e., when the disturbing frequencies are $\omega=10 \mathrm{rad} / \mathrm{s}(\approx 1.6 \mathrm{~Hz})$ and $\omega=20 \mathrm{rad} / \mathrm{s}(\approx 3.2 \mathrm{~Hz}))$ the platform of the robot is not moving. In all the other cases, the system moves step-wisely and translationally with different average speeds. When $\omega=30 \mathrm{rad} / \mathrm{s}(\approx 4.8 \mathrm{~Hz})$, the average speed of the platform equals $0.05 \mathrm{~m} / \mathrm{s}$; when $\omega=40 \mathrm{rad} / \mathrm{s}(\approx 6.4 \mathrm{~Hz})-0.06 \mathrm{~m} / \mathrm{s} ; \quad$ when $\omega=50 \mathrm{rad} / \mathrm{s}(\approx 8 \mathrm{~Hz}) \quad-0.08 \mathrm{~m} / \mathrm{s}$; when $\omega=60 \mathrm{rad} / \mathrm{s}(\approx 9.6 \mathrm{~Hz})-0.04 \mathrm{~m} / \mathrm{s}$. Thus, we can state that maximal motion speed of the system is $0.08 \mathrm{~m} / \mathrm{s}$ is provided at the disturbing frequency of $\omega=50 \mathrm{rad} / \mathrm{s}(\approx 8 \mathrm{~Hz})$. As a result of further increase of the excitation frequency over $50 \mathrm{rad} / \mathrm{s}(\approx 8 \mathrm{~Hz})$, there takes place the reduction of the average motion speed of the platform. Therefore, having substantiated the circular frequency of excitation force, let us analyse the influence of its amplitude value on the motion speed of mobile robot. 
Vitaliy Korendiy

a) $\frac{x_{1}, \mathrm{~m}}{x_{2}, \mathrm{~m}}$

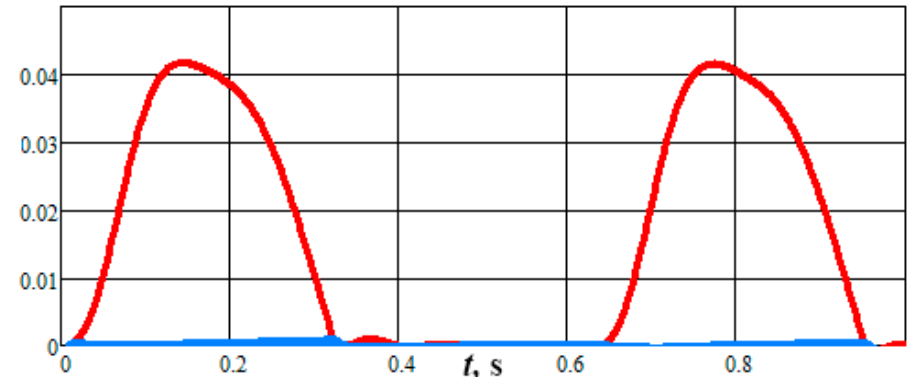

b)

$\frac{x_{1}, \mathrm{~m}}{x_{2}, \mathrm{~m}}$

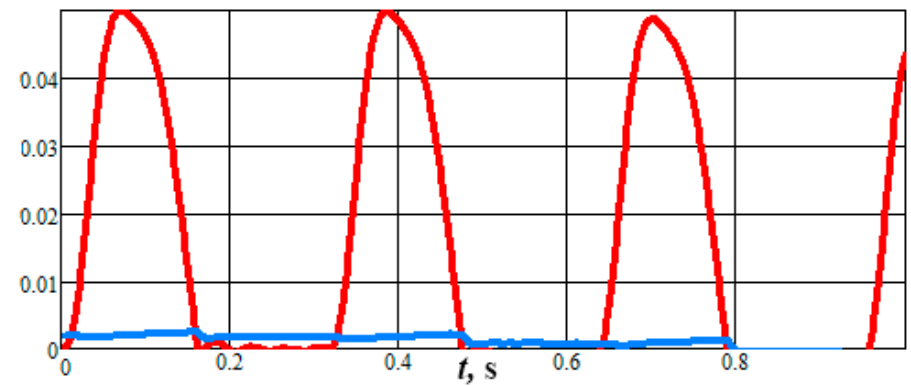

c) $\frac{x_{1}, \mathrm{~m}}{x_{2}, \mathrm{~m}}$

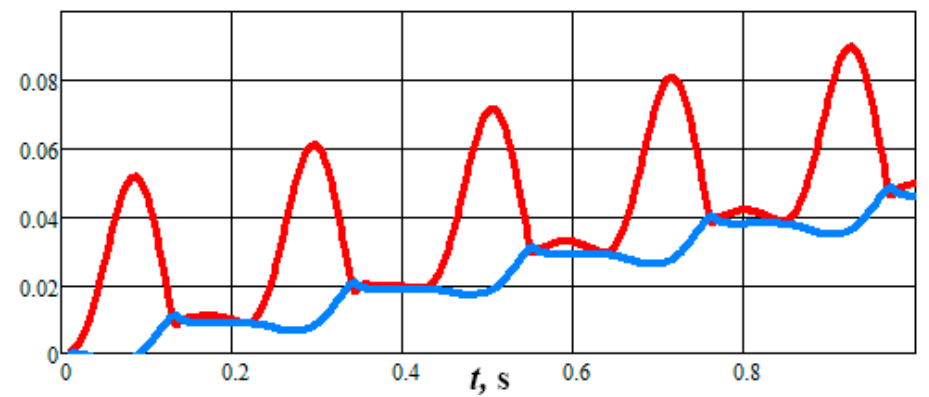

d)

$\frac{x_{1}, \mathrm{~m}}{x_{2}, \mathrm{~m}}$

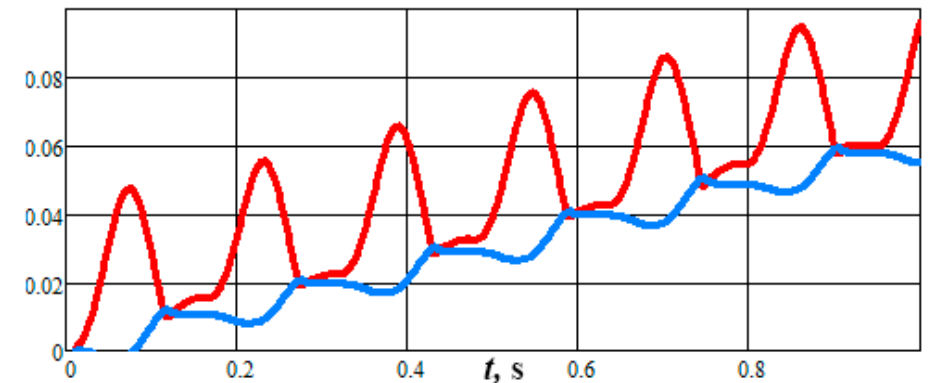

e)

$\frac{x_{1}, \mathrm{~m}}{x_{2}, \mathrm{~m}}$

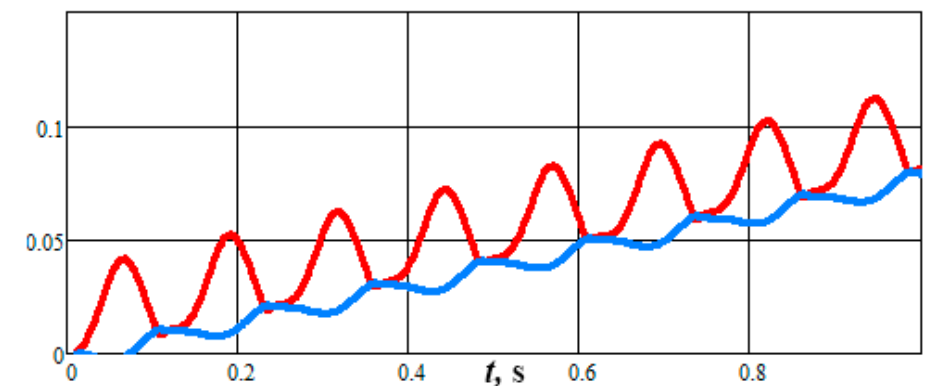

f)

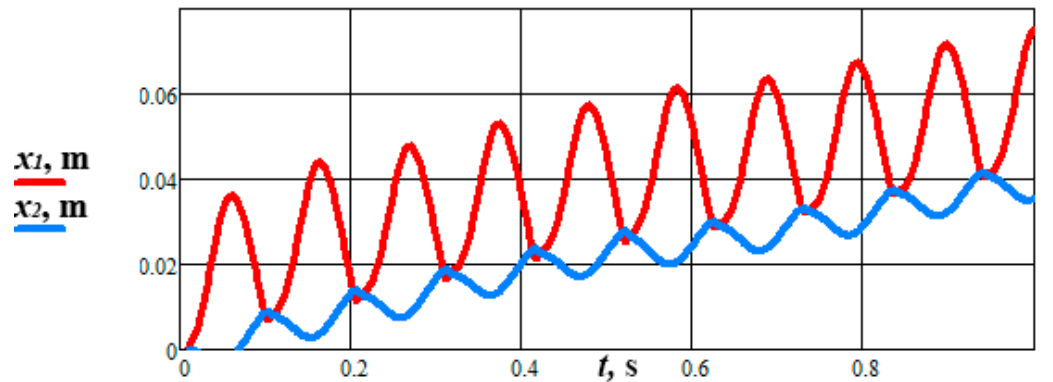

Fig. 6. Time dependencies of the oscillating masses' displacements at different forced frequencies (see Table 1) 


\section{Dynamics of Two-mass Mobile Vibratory Robot with Electromagnetic Drive and Vibro-impact ...}

For the unchanged inertial and stiffness parameters of the robot's mechanical oscillatory system presented above, let us investigate its speed at the following excitation parameters (see Table 2).

Table 2

Excitation parameters of the system with constant frequency of the disturbing force

\begin{tabular}{|l|l|}
\hline a) $F=50 \mathrm{~N}, \omega=50 \mathrm{rad} / \mathrm{s}(\approx 8 \mathrm{~Hz})$ & b) $F=100 \mathrm{~N}, \omega=50 \mathrm{rad} / \mathrm{s}(\approx 8 \mathrm{~Hz})$ \\
\hline c) $F=150 \mathrm{~N}, \omega=50 \mathrm{rad} / \mathrm{s}(\approx 8 \mathrm{~Hz})$ & d) $F=200 \mathrm{~N}, \omega=50 \mathrm{rad} / \mathrm{s}(\approx 8 \mathrm{~Hz})$ \\
\hline e) $F=250 \mathrm{~N}, \omega=50 \mathrm{rad} / \mathrm{s}(\approx 8 \mathrm{~Hz})$ & f) $F=300 \mathrm{~N}, \omega=50 \mathrm{rad} / \mathrm{s}(\approx 8 \mathrm{~Hz})$ \\
\hline
\end{tabular}

The results of modelling the system's motion at the constant excitation frequency $\omega=50 \mathrm{rad} / \mathrm{s}(\approx 8 \mathrm{~Hz})$ and different amplitude values of the disturbing force $50 \mathrm{~N} \leq F \leq 300 \mathrm{~N}$ are presented in Fig. 7.

Analysing the obtained results, we can state that in the case a) (i.e., when the amplitude of the excitation force is $F=50 \mathrm{~N}$ ) the robot's platform is not moving translationally. In all the other cases, the system is moving step-wisely and translationally with different average speeds proportional to the amplitude of the disturbing force. When $F=100 \mathrm{~N}$, the average speed of the platform is $0.08 \mathrm{~m} / \mathrm{s}$; when $F=150 \mathrm{~N}-0.12 \mathrm{~m} / \mathrm{s}$; when $F=200 \mathrm{~N}-0.15 \mathrm{~m} / \mathrm{s}$; when $F=250 \mathrm{~N}-0.17 \mathrm{~m} / \mathrm{s}$, when $F=300 \mathrm{~N}-$ $0.18 \mathrm{~m} / \mathrm{s}$. Thus, we can state that the maximal motion speed of the system of $0.18 \mathrm{~m} / \mathrm{s}$ is provided at the amplitude of the disturbing force of $F=300 \mathrm{~N}$. However, further proportional increase of the amplitude is followed by smaller and smaller increase of the average motion speed of the platform. That is why, at this stage of our investigations, let us adopt the following excitation parameters: $F=300 \mathrm{~N}$, $\omega=50 \mathrm{rad} / \mathrm{s}(\approx 8 \mathrm{~Hz})$.

The obtained results can be used while designing and implementing the control systems of mobile vibratory transporting, technological and robotic systems designed on the basis of the considered structure in order to change their motion speed without changing inertial and stiffness parameters of mechanical oscillatory systems. Basic recommendations related with choosing the excitation parameters for the considered example of mobile vibratory robot can be substantiated on the basis of graphical dependencies presented in Fig. 8. The plot in Fig. 8, a, represents the character of changing the average speed of the platform of mobile vibratory robot when the forced circular frequency varies in the range of $10 \mathrm{rad} / \mathrm{s}(\approx 1.6 \mathrm{~Hz}) \leq \omega \leq 60 \mathrm{rad} / \mathrm{s}(\approx 9.6 \mathrm{~Hz})$ at the amplitude value of the excitation force $F=100 \mathrm{~N}$.

The plot in Fig. 8, b, represents the character of changing the average speed of the platform of mobile vibratory robot when the excitation force varies in the range of $50 \mathrm{~N} \leq F \leq 300 \mathrm{~N}$ at the forced circular frequency $\omega=50 \mathrm{rad} / \mathrm{s}(\approx 8 \mathrm{~Hz})$.

Therefore, analysing the graphical dependencies in Fig. 8, we can state that maximal speed of the system's motion equals $0.18 \mathrm{~m} / \mathrm{s}$ and is provided by the disturbing frequency $\omega=50 \mathrm{rad} / \mathrm{s}(\approx 8 \mathrm{~Hz})$ and the amplitude value of the excitation force $F=300 \mathrm{~N}$. If we continue increasing the forced frequency of the system over $50 \mathrm{rad} / \mathrm{s}(\approx 8 \mathrm{~Hz})$, there takes place the reduction of the average motion speed of the platform. At the same time, further proportional increasing of the amplitude of excitation force (over $300 \mathrm{~N}$ ) is followed by smaller and smaller increase of the average motion speed of the platform.

\section{Simulation of the robot's motion in SolidWorks software}

In order to confirm the results of theoretical investigations carried out by means of numerical solving of the derived differential equations of the system's motion, we decided to perform simulation of the robot's motion in SolidWorks Motion software. Before this, we constructed the solid-state model of mobile vibratory robot in SolidWorks software (see Fig. 9). As a result of performed simulation, the time dependences of the platform displacement and speed will be obtained. 
Vitaliy Korendiy

a) $\frac{x_{1}, \mathrm{~m}}{x_{2}, \mathrm{~m}}$

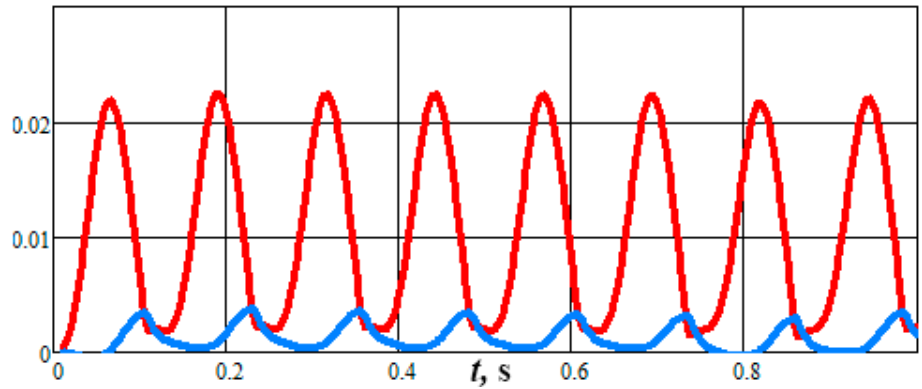

b) $\frac{x_{1}, \mathrm{~m}}{x_{2}, \mathrm{~m}}$

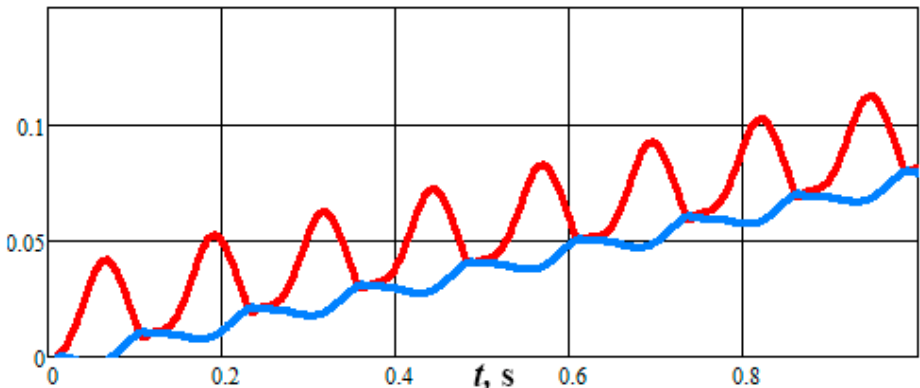

c) $\frac{x_{1}, \mathrm{~m}}{x_{2}, \mathrm{~m}}$

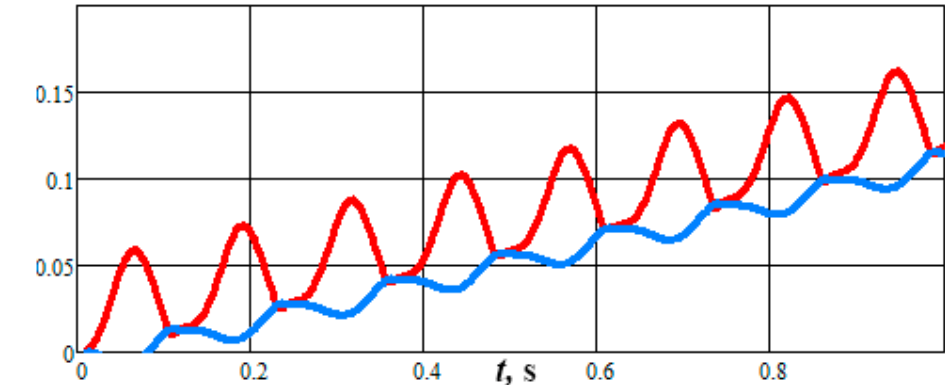

d)

$\frac{x_{1}, \mathrm{~m}}{x_{2}, \mathrm{~m}}$

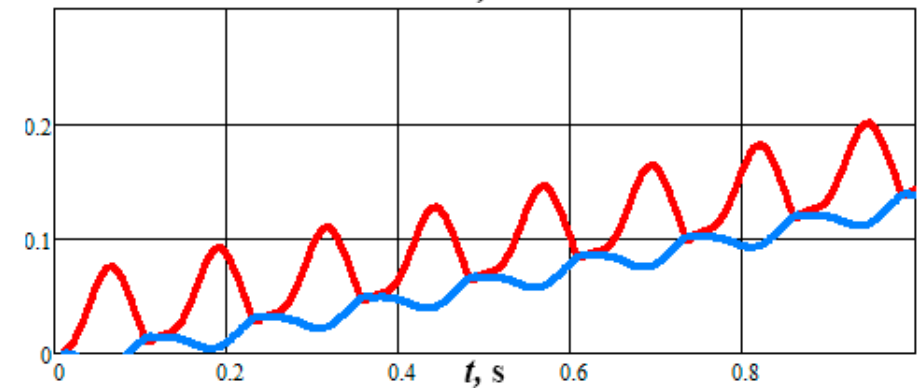

e) $\frac{x_{1}, \mathrm{~m}}{x_{2}, \mathrm{~m}}$

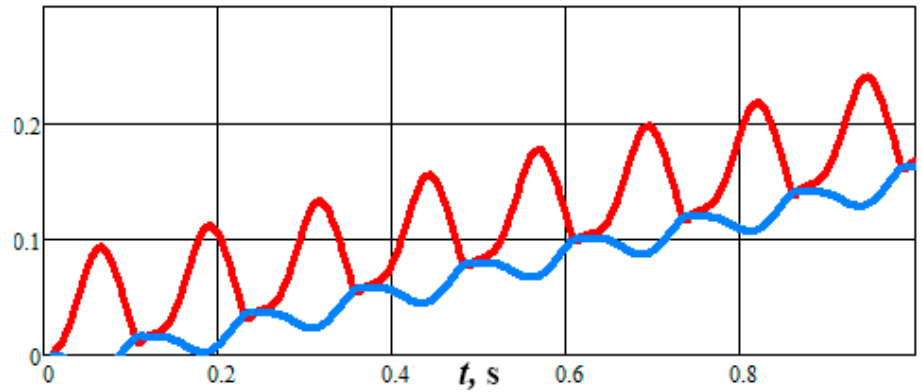

f) $\frac{x_{1}, \mathrm{~m}}{x_{2}, \mathrm{~m}}$

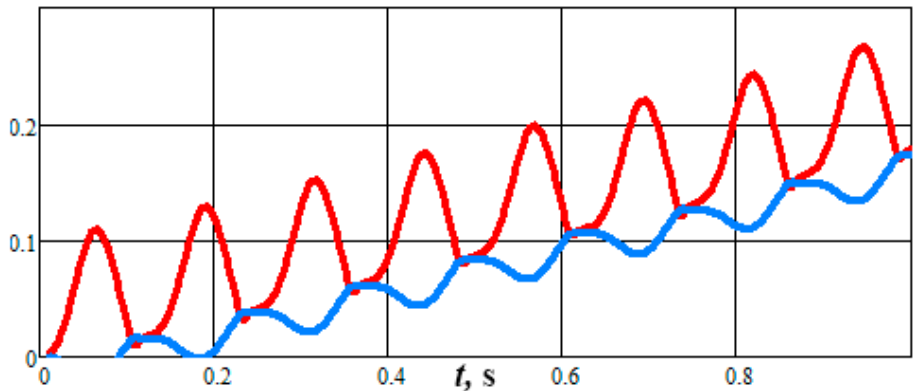

Fig. 7. Time dependencies of the masses' displacements at different amplitudes of the excitation force (see Table 2) 
a)

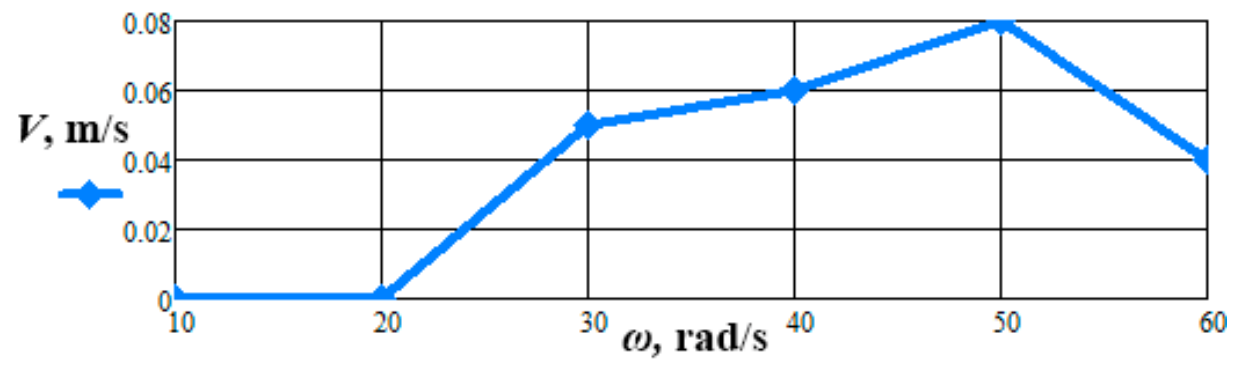

b)

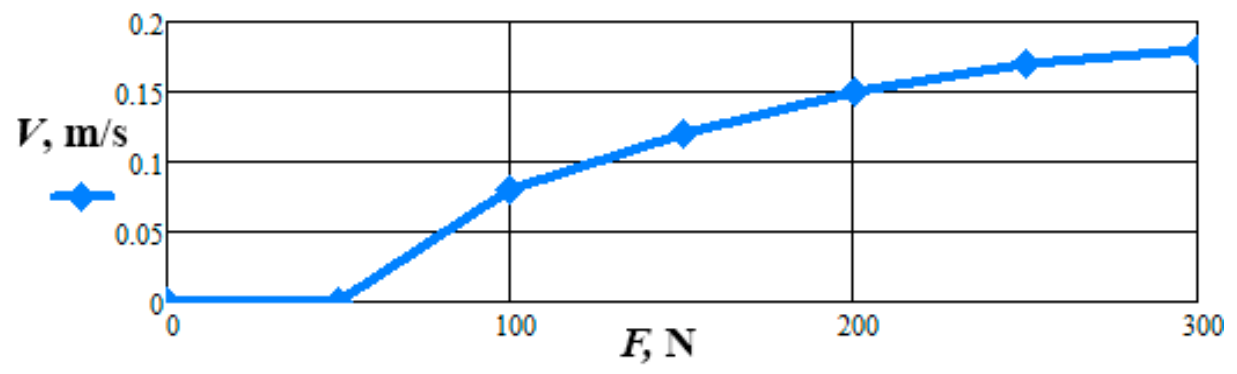

Fig. 8. The dependencies of the average motion speed of mobile vibratory device on the circular frequency (a) and on the amplitude value (b) of the excitation force

While constructing the solid-state model of the mobile vibratory device, the following restrictions were applied on the working bodies of the oscillatory system: 1) the coincidence of the surfaces of contact of the platform with the unmovable supporting plate and of the exciting body with the platform of vibratory device; 2) the coincidence of the lateral surfaces of the working bodies with the lateral surface of the supporting plate; 3) the contacting springs between the working bodies are characterised by constant stiffnesses $c=100 \mathrm{H} / \mathrm{M}$ and $c_{1}=3000 \mathrm{H} / \mathrm{m}$ with the linear law of changing the elasticity force depending on the relative displacement of bodies; the energy dissipation in springs is neglected $\left(\mu=\mu_{1}=0\right)$; 4$)$ the friction forces between the contacting surfaces of the platform and the supporting plate are constant; they are characterized by friction coefficient $f_{1}=0.17$ and depend only on the direction of the platform's motion; 5 ) the friction between the contacting surfaces of the exciting body and the platform is neglected $\left(f_{2}=0\right)$; 6) the excitation force is determined by the alternating (sinusoidal) law with the amplitude of $300 \mathrm{~N}$ and the circular frequency of $50 \mathrm{rad} / \mathrm{s}(8 \mathrm{~Hz}) ; 7)$ the working bodies of the system are manufactured of plain carbon steel (Steel 3) and their geometrical sizes are adopted in such a way to ensure the corresponding inertial parameters of the oscillatory system $m=0.25 \mathrm{~kg}, M=5.5 \mathrm{~kg}$.

In Fig. 10, there are presented the results of simulation (modelling) of motion of the two-mass mechanical oscillatory system of mobile vibratory device with vibro-impact operation mode obtained in SolidWorks software. Analysing these graphical dependencies and comparing them with the results of analytical investigations (Figs. 6 and 7), we can conclude their satisfactory reproducibility that substantiate the adequacy of the proposed mathematical models for describing the dynamics of the mobile vibratory device and of the numerical modelling of the robot's motion carried out in MathCAD software and presented above. Some noticeable differences can be explained by the difficulty of modelling the friction between the contacting surfaces, since the SolidWorks software, when setting the appropriate materials (e.g., "dry steel - dry steel"), takes into account not only static friction, but also kinematic and viscous friction, which causes the absence of the platform movement in the opposite direction. On the plot of Fig. 10, it is clearly seen that the active mass (platform) moves step-wisely in the positive direction of the $O x$ axis (see blue line), whereas according to the results of the theoretical (numerical) modelling (Figs. 6 and 7, blue line), the platform carries almost the same oscillatory motion in the horizontal direction. Thus, in general, the average speed of the body of the mobile vibratory device is about $0.18 \mathrm{~m} / \mathrm{s}$, the maximum amplitude of the deflection of the disturbing body from the instantaneous equilibrium position is $0.12 \mathrm{~m}$, the distance passed by the robot's platform per unit step is about $0.025 \mathrm{~m}$, which with sufficient accuracy match the results of theoretical investigations obtained in MathCAD software (see Figs. 6 and 7). 


\section{Vitaliy Korendiy}

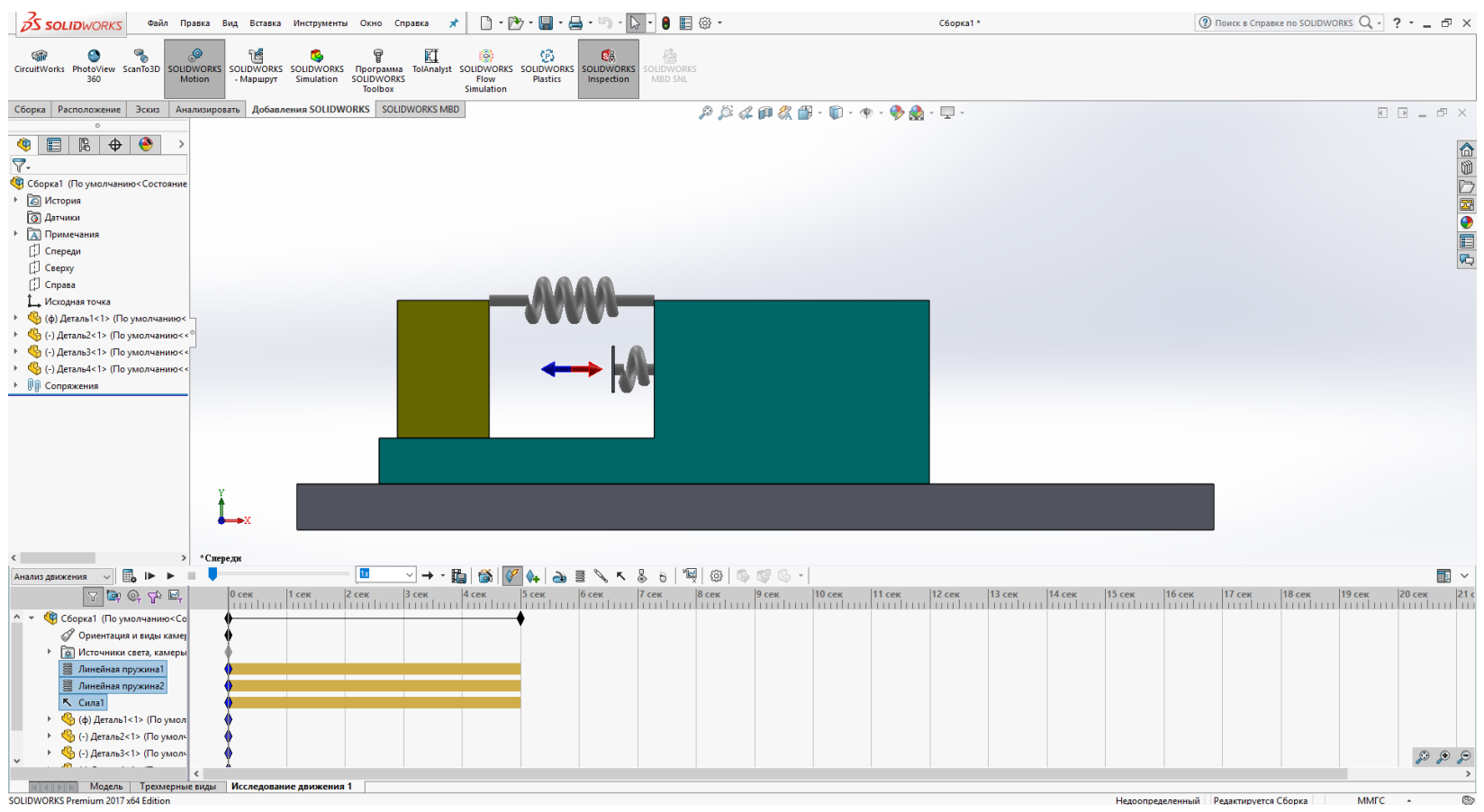

Fig. 9. The SolidWorks software window in which the simulation of the robot's motion was carried out

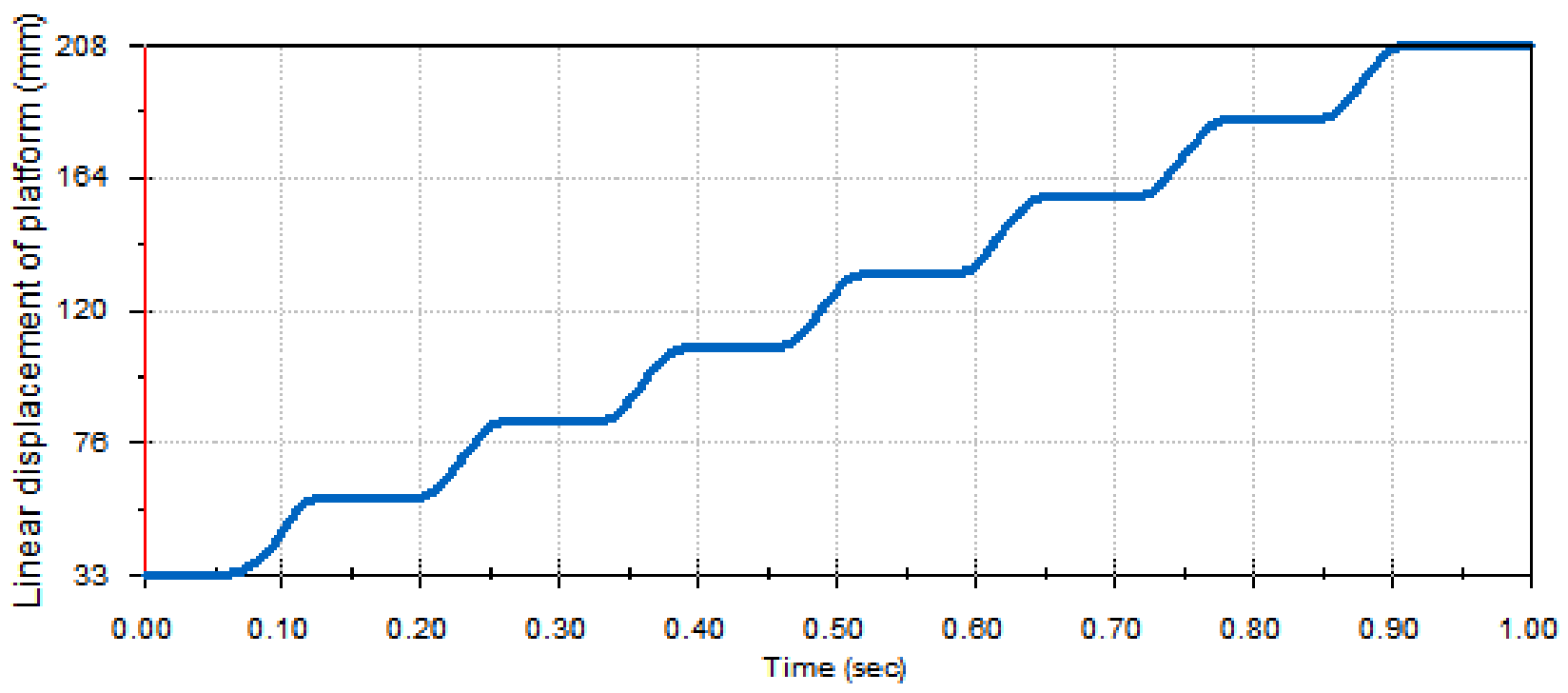

Fig. 10. Results of simulation of the robot's motion obtained in SolidWorks software

\section{Conclusions}

In the present paper, there is proposed the principal diagram of mobile vibratory device with vibroimpact operation mode. The device is designed on the basis of two-mass oscillatory system with an active mass moving on the stationary supporting plate (surface) and with a reactive mass places inside the body of the vibratory device and attached to the active mass with a help of elastic element (cylindrical coil spring). The peculiarities of operation and fields of application of the proposed mobile vibratory device are considered. The main forces acting on the elements of its mechanical oscillatory system were analysed and the mathematical model describing its motion under the action of sinusoidal excitation force applied between the active and reactive masses was developed on the basis of Lagrange second order equations.

The motion of the mobile vibratory device was modelled by means of numerical solving of the derived differential equations in MathCAD software. The oscillatory motions of the working bodies were analysed; maximal amplitudes of their displacements from the instantaneous equilibrium position, as well as instantaneous and average motion speeds, were estimated; the possibilities of changing the speed of the 


\section{Dynamics of Two-mass Mobile Vibratory Robot with Electromagnetic Drive and Vibro-impact ...}

system's motion, its accelerating and decelerating by means of changing the frequency and the amplitude of the excitation force were substantiated.

The influence of the circular frequency and the amplitude of excitation force on the average speed of the robot's platform was analysed. In particular, the cases of changing the forced frequency in the range of $10 \mathrm{rad} / \mathrm{s}(\approx 1.6 \mathrm{~Hz}) \leq \omega \leq 60 \mathrm{rad} / \mathrm{s}(\approx 9.6 \mathrm{~Hz})$ and changing the amplitude value of the excitation force in the range of $50 \mathrm{~N} \leq F \leq 300 \mathrm{~N}$ were considered. The expediency of using the forced frequency of $\omega=50 \mathrm{rad} / \mathrm{s}(\approx 8 \mathrm{~Hz})$ and the amplitude of $F=300 \mathrm{~N}$ for ensuring the platform's maximal horizontal speed of $0.18 \mathrm{~m} / \mathrm{s}$ was substantiated.

The simulation of the robot's motion was performed with a help of its soli-state model designed in SolidWorks software. The comparative analysis of the results of theoretical studies and virtual experiment was carried out. The satisfactory reproducibility that substantiate the adequacy of the proposed mathematical models for describing the dynamics of the mobile vibratory device and of the numerical modelling of the robot's motion carried out in MathCAD software.

The possibilities of using the results of the carried out investigations while designing and implementing the control systems of mobile transporting, technological and robotic systems developed on the basis of the similar structure for changing their motion speed were considered. While carrying out further investigations it is necessary to study the possibility of changing the nonlinearity of stiffness characteristic of the elastic element in order to change the kinematic parameters of the system's motion, as well as to substantiate the mechanisms of changing the direction of motion of mobile vibratory robot.

\section{References}

[1] N. Bolotnik, I. Zeidis, K. Zimmermann, and S. Yatsun, "Vibration driven robots", in Proc. 56th International Scientific Colloquium "Innovation in Mechanical Engineering - Shaping the Future", Ilmenau University of Technology, Ilmenau, Germany, 12-16 September 2011, pp. 1-6.

[2] I. Loukanov, V. Vitliemov, S. Stoyanov, and S. Stoyanov, "Design developments of vibration-driven robots," in Proceedings of 56th Science Conference of Ruse University, 2017, pp. 50-59.

[3] T.-H. Duong, V.-D. Nguyen, and N.-T. La, "A new autogenous mobile system driven by vibration without impacts, excited by an impulse periodic force," MATEC Web Conf., vol. 148, p. 04005, 2018.

[4] N. N. Bolotnik, I. M. Zeidis, K. Zimmermann, and S. F. Yatsun, "Dynamics of controlled motion of vibration-driven systems," J. Comput. Syst. Sci. Int., vol. 45, no. 5, pp. 831-840, 2006.

[5] S. F. Yatsun, A. V. Razinkova, and A. N. Grankin, "Issledovanie dvizheniia vibrorobota s elektromagnitnym privodom" ["Investigation of the movement of a vibro-robot with an electromagnetic drive"], Izvestiia vysshikh uchebnykh zavedenii. Mashinostroenie [Proceedings of higher educational institutions. Mechanical Engineering], no. 10, pp. 53-64, 2007.

[6] A. N. Grankin and S. F. Yatsun, "Investigation of vibroimpact regimes of motion of a mobile microrobot with electromagnetic drive," J. Comput. Syst. Sci. Int., vol. 48, no. 1, pp. 155-163, 2009.

[7] A. N. Grankin and S. F. Yatsun, "Issledovanie vibroudarnykh rezhimov dvizheniia mobilnogo mikrorobota s elektromagnitnym privodom" ["Study of vibro-impact movement modes of a mobile microrobot with an electromagnetic drive"]" Izvestiia Rossiiskoi akademii nauk. Teoriia i sistemy upravleniia [Proceedings of the Russian Academy of Sciences. Theory and systems of control], no. 1, pp. 163-171, 2009.

[8] K. A. Sapronov, A. A. Cherepanov, and S. F. Yatsun, "Investigation of motion of a mobile two-mass vibration-driven system," J. Comput. Syst. Sci. Int., vol. 49, no. 1, pp. 144-151, 2010.

[9] Y. Yan, Y. Liu, J. Páez Chávez, F. Zonta, and A. Yusupov, "Proof-of-concept prototype development of the self-propelled capsule system for pipeline inspection," Meccanica, vol. 53, no. 8, pp. 1997-2012, 2018.

[10] Y. Yan et al., "Optimization and experimental verification of the vibro-impact capsule system in fluid pipeline," Proc. Inst. Mech. Eng. Part C J. Mech. Eng. Sci., vol. 233, no. 3, pp. 880-894, 2019.

[11] V. M. Korendiy, "Substantiation of parameters and motion modelling of two-mass mobile vibratory system with two unbalanced vibration exciters", Avtomatizaciâ virobničih procesìv u mašinobuduvannì ta priladobuduvanni [Industrial Process Automation in Engineering and Instrumentation], no. 52, p. 71-80, 2018.

[12] V. Gursky, I. Kuzio, and V. Korendiy, "Optimal Synthesis and Implementation of Resonant Vibratory Systems,” Univers. J. Mech. Eng., vol. 6, no. 2, pp. 38-46, 2018. 